\title{
NEWS
}

\section{Dentists back Healthwatch call to fix system in crisis}

The British Dental Association has backed calls from patient champion Healthwatch for the Government to act on the ongoing crisis in dental services in England that has been cast into stark relief by the COVID-19 pandemic.

In its latest report the group highlights an unprecedented $452 \%$ rise in calls and complaints about dentistry over the summer, with their Chair, Sir Robert Francis QC, urging Government to act to resolve 'both long-standing and COVID-19-related issues in dentistry.

Between March and the end of August 14.5 million fewer NHS dental procedures took place in England. The BDA has estimated that figure rose to over 19 million by the end of October.

Owing to official restrictions, $70 \%$ of practices are now operating at less than half their pre-pandemic capacity. $55 \%$ of practices estimate they can maintain their financial sustainability for 12 months or less.

Prior to the pandemic unmet need for NHS dental services in England was estimated at over 4 million people over 18 , or nearly 1 in 10 of the adult population with families in Portsmouth facing ferry rides and patients in parts of Cornwall round trips of up to 120 miles to access care.

The widely discredited, target-driven NHS contract - dubbed by the Commons Health Committee as 'unfit for purpose' - funded care for little over half the population before the pandemic and prompted a collapse in morale within the workforce.

The BDA has urged current Health and Social Care Committee Chair Jeremy
Hunt MP to resume the inquiry initiated in the last Parliament that was canned by the snap general election at the end of 2019.

British Dental Association Chair Eddie Crouch said: 'For many people dentistry effectively ceased to exist at lockdown, as a system already in crisis was pushed ever closer to the brink.

'The difference now is problems that have dogged families from Cornwall to Cumbria for decades are now the reality in every community in the UK.

'The arrival of COVID-19 vaccines will not solve the problems facing millions of our patients. Sadly 'business as usual' in dentistry means postcode lotteries, failed contracts, and underfunding.

'The Government says the mantra is 'build back better'. It must apply that logic to dental services.'

Responding to the report John Makin, head of the DDU, said: 'We note the findings of the Healthwatch report and sympathise with patients who are experiencing the difficulties described in accessing dental care. Dental professionals understand patient's frustrations and are working within the current system and restrictions to provide high quality care.

'Patients have been understanding on the whole but, as the report shows, some are dissatisfied with long-standing contractual issues on patient registration and the difficulties caused by the pandemic, which are not of individual practitioners' making. For example, the backlog of patients requiring treatment caused by the suspension of routine care during the first lockdown and the restrictions now in place on numbers of patients who can be seen and treatments available.

'At the DDU we are already seeing the impact of the pandemic in the number of complaints we are supporting our members with and cases are unfortunately likely to increase. When examining the current situation, it's really important that the context in which colleagues are currently working is taken into account.'

Susie Sanderson, Dentolegal Consultant at Dental Protection, reiterated the extremely challenging environment for dental professionals.

'Dentists have faced a range of challenges throughout the pandemic, and many have returned to practise in equally challenging circumstances adapting to additional PPE and new ways of working, worrying about their health and that of their staff and patients, and facing a significant backlog of patients with outstanding treatment due to the unavoidable delays. $45 \%$ of UK dentists say their mental wellbeing is worse compared to the start of the pandemic.

'Many dentists have also expressed their frustration that guidelines are not always easy to decipher and adhere to and are having an adverse impact on the operating capacity of the practices.

'The delays and disruption frustrate patients, but also create stress for dentists, who are doing their best but feel they cannot always act in their patients' best interests for reasons beyond their control.'

\section{NEWS}

\section{£500 gift no substitute for decent pay}

The British Dental Association Scotland has said that the $£ 500$ 'gift' to frontline NHS workers is no substitute for long-term commitments to above-inflation pay awards.

The pledge, made by the First Minister in her keynote speech to the Scottish National Party conference, could benefit up to 300,000 NHS and social care workers, but has received widespread criticism from healthcare unions for tokenism after a decade of pay restraint.

The one-off payment will be pro-rataed for those not working full time within the NHS. BDA Scotland is now seeking details on the mechanics of the reward, particularly for the majority of dentists and team members working in 'mixed' practice.

There remains real uncertainty over whether the gift will be tax-free.
Robert Donald, Chair of the British Dental Association's Scottish Council said: 'We are pleased to see some recognition for frontline staff, but $£ 500$ will not make up for a decade of pay restraint that's hit colleagues in every NHS practice, hospital and clinic in Scotland.

'If the Scottish Government really wants to say thank you to this service it will ensure pay cuts remain a thing of the past.' 